\title{
In Reference to Effects of Preoperative Anxiety on Postoperative Delirium in Elderly Patients [Letter]
}

\author{
Cheng-Wen Li $\mathbb{D}$ \\ Fu-Shan Xue \\ Hai-Jun Hou (ID
}

Department of Anesthesiology, Beijing Friendship Hospital, Capital Medical

University, Beijing, People's Republic of China
Correspondence: Fu-Shan Xue Department of Anesthesiology, Beijing Friendship Hospital, Capital Medical University, No. 95 Yong-An Road, XiCheng District, Beijing, I00050, People's Republic of China

$\mathrm{Tel}+86-1391 \mid 177655$

Fax + 86-10-63138362

Email xuefushan@aliyun.com

\section{Dear editor}

By a prospective observational cohort study, Ren et al. ${ }^{1}$ assessed the effect of preoperative anxiety on postoperative delirium (POD) in elderly patients undergoing elective orthopedic surgery. By multivariate logistic regression analysis, they showed that preoperative Mini Mental State Examination score and anxiety were independently associated with the development of POD. Although the valuable study has been actualized, there are several methodological issues in this article on which we wish to invite the authors to comment.

First, in statistical analyses, the authors described that the logistic regression models were used to assess the influence of different variables on outcomes. The variables with a $\mathrm{P}<0.05$ in the univariate analysis were included in the multivariate model to control confounding factors. Furthermore, the variance inflation factors were applied to examine possible collinearity among covariate variables. However, the readers were not provided the results of univariate analysis and collinearity analyses among covariate variables by variance inflation factors. We noted that all variables with a $\mathrm{P}<0.05$ in the initial bivariate analyses for demographics, clinical and surgical data between patients with and without POD in tables 1 and 2 of the Ren et al. article were entered into the multivariate model for statistical adjustment. This process of modeling may be questionable. Generally speaking, after the initial bivariate analyses of demographics and perioperative data between patients with and without a POD, the variables with statistical significance, defined as $\mathrm{P}<0.05$, should be entered into the univariate model to examine multicollinearity among candidate covariate variables. Then, the covariate variables with large $\mathrm{P}$ values $(\mathrm{P}<0.2)$ in the univariate analyses are included in the multivariate model using POD as the dependent outcome variable for adjustment to identify the independent factors of POD, with their $\mathrm{P}$ values, adjusted odds ratios and $95 \%$ confidence intervals. $^{2}$ As this study did not use the univariate analyses to examine multicollinearity among candidate covariate variables obtained in the initial bivariate analyses and did not report the results of collinearity analyses among covariate variables by variance inflation factors, we are concerned that their results of multivariate logistic regression analyses would have been biased.

Second, the development of POD actually is the result of complex interactions among many perioperative predisposing and precipitating factors. ${ }^{3}$ As POD was assessed for 5 days following surgery in this study, an important limitation of study design was that most postoperative factors associated with an increased risk of POD 
were not taken into account when assessing the association of preoperative anxiety with POD by the multivariate analysis. Other than ICU admission described in this study, available evidence indicates that early postoperative complications and adverse events, such as pneumonia, acute kidney injury, prolonged hospitalization, sleep deprivation and disorders, and immobilizing events, are significant risk factors for POD in elderly surgical patients. ${ }^{4-6}$ Thus, we argue that not taking postoperative complications and adverse events associated with an increased risk of POD into the model for adjustment would have distorted the inferences of the multivariate analysis in this study.

Finally, patient-controlled intravenous analgesia was used as a postoperative outcome variable. As application proportion of patient-controlled intravenous analgesia was not significantly different between patients with and without POD, this variable was not included in the multivariate model. In fact, the authors should describe whether postoperative pain level was comparable between patients with and without POD, as inadequate postoperative pain control has been identified as an independent risk factor for POD. ${ }^{7}$

\section{References}

1. Ren A, Zhang N, Zhu H, Zhou K, Cao Y, Liu J. Effects of preoperative anxiety on postoperative delirium in elderly patients undergoing elective orthopedic surgery: a prospective observational cohort study. Clin Interv Aging. 2021;16:549-557. doi:10.2147/CIA.S300639

2. Grant SW, Hickey GL, Head SJ. Statistical primer: multivariable regression considerations and pitfalls. Eur J Cardiothorac Surg. 2019;55(2):179-185. doi:10.1093/ejcts/ezy403

3. Olotu C. Postoperative neurocognitive disorders. Curr Opin Anaesthesiol. 2020;33(1):101-108. doi:10.1097/ACO.0000000000000812

4. Tse L, Schwarz SK, Bowering JB, Moore RL, Barr AM. Incidence of and risk factors for delirium after cardiac surgery at a quaternary care center: a retrospective cohort study. J Cardiothorac Vasc Anesth. 2015;29(6):1472-1479. doi:10.1053/j.jvca.2015.06.018

5. Nazemi AK, Gowd AK, Carmouche JJ, Kates SL, Albert TJ, Behrend CJ. Prevention and management of postoperative delirium in elderly patients following elective spinal surgery. Clin Spine Surg. 2017;30(3):112-119. doi:10.1097/BSD.0000000000000467

6. Kotfis K, Szylińska A, Listewnik M, et al. Early delirium after cardiac surgery: an analysis of incidence and risk factors in elderly ( $\geq 65$ years) and very elderly $(\geq 80$ years $)$ patients. Clin Interv Aging. 2018;13:1061-1070. doi:10.2147/CIA.S166909

7. Lin YT, Lan KM, Wang LK, et al. Incidence, risk factors, and phenomenological characteristics of postoperative delirium in patients receiving intravenous patient-controlled analgesia: a prospective cohort study. Neuropsychiatr Dis Treat. 2016;12:3205-3212. doi:10.2147/NDT. S119817

\title{
Disclosure
}

All authors have no financial support and potential conflicts of interest for this communication.

\begin{abstract}
Dove Medical Press encourages responsible, free and frank academic debate. The content of the Clinical Interventions in Aging 'letters to the editor' section does not necessarily represent the views of Dove Medical Press, its officers, agents, employees, related entities or the Clinical Interventions in Aging editors. While all reasonable steps have been taken to confirm the content of each letter, Dove Medical Press accepts no liability in respect of the content of any letter, nor is it responsible for the content and accuracy of any letter to the editor.
\end{abstract}

Clinical Interventions in Aging

Dovepress

\section{Publish your work in this journal}

Clinical Interventions in Aging is an international, peer-reviewed journal focusing on evidence-based reports on the value or lack thereof of treatments intended to prevent or delay the onset of maladaptive correlates of aging in human beings. This journal is indexed on PubMed Central, MedLine, CAS, Scopus and the Elsevier
Bibliographic databases. The manuscript management system is completely online and includes a very quick and fair peer-review system, which is all easy to use. Visit http://www.dovepress.com/ testimonials.php to read real quotes from published authors. 